\title{
Strengthening student support Offering TRiO Student Support Services in the library
}

M any units on campus play a significant role in student success. Individually, these departments provide services and staff to assist students with various aspects of college life. When these entities collaborate, the impact they have is multiplied and can make services more accessible to students. One such partnership, between the library and TRiO Student Support Services (SSS) at the Miami University-Hamilton Campus, is discussed in this article.

Federal TRiO SSS programs serve students who are either first generation, or meet low income guidelines defined by the U.S. Department of Education, or who have a documented disability. While this collaboration has met its main goal of providing support services to academically at-risk students, it has had the added benefit of increasing the library's relevance on campus by demonstrating that the library plays an active role in increasing retention and student success. This collaboration also contributes directly to the interim dean's stated priority to increase enrollment and retention at the Miami University Regional Campuses.

\section{Campus and student information}

Nestled several blocks from the main street through downtown Hamilton, Ohio, the Hamilton Regional Campus of Miami University sits on the Miami River and on the edges of a few neighborhoods. This puts Miami Hamilton in an ideal location to reach a diverse range of students. It is within walking distance from home for students who do not have other means to get to campus, and a short drive for others who need to take classes during their children's school day or right after work. Convenience and affordability are necessities for most seeking a college degree in the region.

Miami University's Regional Campuses (Regionals) in Hamilton and Middletown have traditionally been, and continue to be, feeder schools for the main campus in Oxford. However, the Regionals have recently developed many four-year degree programs that can be completed without transferring to the main campus. This constitutes a major step forward for the Regionals, and provides further opportunities to meet the educational needs of local communities. The campuses' open admission policy makes getting a college degree an attainable goal for everyone.

Considering the demographic characteristics of potential students in surrounding communities, the Regionals market themselves as a convenient option for pursuing higher education. Like students at many community colleges and regional

Carrie Girton is public services librarian, email: girtonc@ miamioh.edu, Krista McDonald is library director, mcdonak@miamioh.edu, and Jamie E.Viars is academic coach, TRiO Student Support Services at Miami University, email: viarsje@miamioh.edu

일 2018 Carrie Girton, Krista McDonald, and Jamie E. Viars 
campuses, students at the Regionals often face life challenges while they are attending school. Some of them come from a low socioeconomic status, are the first in their families to attend college, or are juggling full-time jobs while raising children and attending school. As a result, the Regionals were ideal candidates for a TRiO SSS grant.

\section{TRiO SSS at Miami University Regionals}

The five-year, \$1.1 million grant was awarded to the Regionals in September 2015. The program is housed in Rentschler Library at the Miami University-Hamilton Campus, and in Gardner-Harvey Library at the Miami University-Middletown Campus. This article focuses on the experience of Rentschler Library staff and the TRiO SSS academic coach at Hamilton.

A variety of factors influenced the decision to house the TRiO SSS program in the campus library. The department heads of the two units most affected by the decision to locate TRiO SSS in the library both felt strongly that this was the best location for the program. The director of the Hamilton campus library was eager to host the program, as she felt that library staff would assist with information literacy skills and technical support that SSS students would need.

In her opinion, students should spend the bulk of their time on campus, where resources and academic support services outside the TRiO SSS program are most available.

As environment impacts behavior, the director of the Office of Learning Assistance, who applied for the grant, also felt the library was the ideal place for SSS. Being in the library would encourage students to engage in study, research, and writing. Campus administrators took into consideration such factors as renovation requirements and size of the available space in choosing the final location for the program. Minor, relatively inexpensive alterations could be made quickly in the library, which gave it the edge compared to other potential locations.

\section{Impact of Libraries on Student Success}

A review of the literature shows that academic libraries play a role in student academic achievement and in university retention efforts. Library impacts on student success can be divided into two categories, academic and nonacademic, which are particularly relevant to the students who meet the eligibility criteria for inclusion in the TRiO SSS program as described above. Academic impacts have a measurable effect on GPA and retention or graduation rates, such as use of electronic journals to complete research assignments. Nonacademic impacts include services or student support that may not directly impact GPA, but nevertheless contribute to retention, such as assistance with learning how to register for classes online.

\section{Libraries' academic impacts on student success}

Multiple studies have found that use of library resources and services has a positive impact on students' GPA, retention, or graduation rates. ${ }^{1}$ These services have a particularly strong influence on students from lower socioeconomic status. Given that many students in the Miami Regionals TRiO SSS program live within or below federal poverty guidelines, library resources and services are essential to their academic success. For this reason, there are two computer workstations in the SSS area of the library that are designated for SSS students' use only. These two workstations also provide free printing, while the rest of the library's public computers are connected to the university's pay-forprint system.

In addition to the physical items provided by the library, services from the library staff, such as providing reference assistance, helping with citations, and troubleshooting technology and formatting issues, are invaluable to these students. Incorporating the TRiO SSS space in the library gives students more immediate access to library staff when these types of questions arise. 
To increase their use of these services and reduce library anxiety, library staff recently proposed a personal librarian program for the SSS students. As previously mentioned, one of the initial reasons for housing the TRiO SSS program in the library space is because the library is conducive to studying and would encourage the students to focus on studying and coursework.

\section{Libraries' nonacademic impacts on student success}

Studies have also shown that "libraries as place" serve an important role for college students. ${ }^{2}$ This is especially important on a nonresidential campus such as Miami University-Hamilton, since students typically build these relationships in residence halls at four-year residential campuses. Libraries deliver social supports by providing spaces where students can study together and engage in academic socializing. ${ }^{3}$ To help facilitate this for TRiO SSS students, Rentschler Library recently went through a renovation and replaced old, heavy wooden furniture with lightweight furniture with casters so that students can configure the space to work in groups or study alone.

One of the goals of the TRiO SSS program is for students to develop a strong network of support within their cohort, and the spaces provided in the library are an excellent place for those relationships to grow. Students visit the SSS space to meet with the staff for coaching meetings, work with the professional tutors, work on homework, grab a snack, print papers and assignments, or simply hang out between classes. As the semesters progress, students see each other in the SSS space regularly and begin to develop relationships with each other. Visiting the SSS space regularly increases their sense of having a supportive place and group of people on campus who care about their success both inside and outside of the classroom.

Jacqui D. Grallo, Mardi Chalmers, and Pamela G. Baker found that students often turn to the library for assistance in adapting to life on a college campus. ${ }^{4}$ This has certainly been librarians' experience at Rentschler Library. Students visit the library seeking assistance with registering for classes online, ordering books from the online bookstore, and paying tuition and other bills online. Library staff also field questions about technology, ranging from how to navigate the university's learning management system to basic questions about productivity software to very detailed questions about course-specific software such as SPSS or Logger Pro. Students also consult with librarians about where to get help with seemingly simple tasks like how to identify their academic advisor, how to drop a course, or how to edit a paper, to the more complex, such as making referrals to student counseling services or even to the TRiO Student Support Services program. Library staff often find themselves helping students navigate the bureaucracy of the university environment. Assistance with this acculturation process is helpful for any student population, but it may be critical for TRiO SSS students who are the first in their families to attend college and who lack parental support and experience with this transition. Having the SSS space within the library serves many purposes for students, and allows students' questions to be answered after standard business hours and on weekends when the TRiO SSS center is not staffed, but the library is open.

\section{Conclusion}

The shared goal of increasing student success has made the collaboration between the library staff and TRiO SSS staff particularly impactful. Open communication between these units facilitates this working relationship and increases the ultimate benefits students receive from the partnership. A recent library renovation expanded the TRiO SSS area and added reconfigurable furniture, which has influenced the way students use the space and interact with one another, directly affecting the academic and nonacademic impact the library has on their success.

TRiO SSS student interviews also indicate that the program's location in the library 
positively impacts their academic success and student experience in the SSS program.

Academic libraries today are often approached by campus or university administrators in search of space for new projects, and library deans and directors must fight to maintain control over the limited space in their buildings. At Miami UniversityHamilton, library staff believed that students would be best served by a partnership with the TRiO SSS program and advocated to bring this program into the library's space. This collaborative effort to improve retention and increase student success emphasized the library's role as a valuable and relevant student resource to the entire campus community.

\section{Notes}

1. Krista M. Soria, Jan Fransen, and Shane Nackerud, "Stacks, Serials, Search Engines, and Students' Success: First-Year Undergraduate Students' Library Use, Academic Achievement, and Retention," The Journal of Academic Librarianship 40, no. 1 (January 1, 2014): 84-91, doi:10.1016/j. acalib.2013.12.002; John K. Stemmer and David M. Mahan, "Assessing the Library's Influence on Freshman and Senior Level Outcomes with User Surveys," Evidence
Based Library and Information Practice 10, no. 2 (January 1, 2015): 8-20. doi:10.18438 /B8PG62; Adam Murray, Ashley Ireland, and Jana Hackathorn, "The Value of Academic Libraries: Library Services as a Predictor of Student Retention," College and Research Libraries 77, no. 5 (September 1, 2016): 631642, doi:10.5860/crl.77.5.631; Gaby Haddow and Jayanthi Joseph, "Loans, Logins, and Lasting the Course: Academic Library Use and Student Retention," Australian Academic and Research Libraries 41, no. 4 (December 1, 2010): 233-244. doi:10.1080/00048623.20 10.10721478 .

2. Kellian D. Clink, "The Academic Library's Role in Student Retention," PNLA Quarterly (Fall 2015): 20-24.

3. Joseph R. Matthews, "Assessing Library Contributions to University Outcomes: The Need for Individual Student Level Data," Library Management 33, no. 6/7 (September 2012): 389-402, doi:10.1108/01435121211266203.

4. Jacqui D. Grallo, Pamela G. Baker, and Mardi Chalmers, "How Do I Get a Campus ID? The Other Role of the Academic Library in Student Retention and Success," Reference Librarian 53, no. 2 (April 1, 2012): 182-193, doi:10.1080/02763877.2011.618787. ఇ

("Minimizing and addressing implicit bias in the workplace," continues from page 481)

12. Textio, https://textio.com /products/.

13. Jay J. Van Bravel and Tessa West, "Seven Steps to Reduce Bias in Hiring," Wall Street Journal, February 21, 2017, accessed July 12, 2018, https://www.wsj. $\mathrm{com} /$ articles/seven-steps-to-reduce-bias-in -hiring-1487646840.

14. Ibid.

15. Ibid.

16. Jon-Mark Sabel, "5 Steps to Reduce Bias in the Workplace," HireVue, April 23, 2018, accessed July 8, 2018, https://www.hirevue.com/ blog/5-steps-to-mitigating-bias-in-the-workplace.
17. "Compensating Fairly," Project Include, http://projectinclude.org /compensating_fairly\#.

18. Sabel, "5 Steps to Reduce Bias in the Workplace."

19. Kathy Sherwood, "10 Ways You Can Reduce Bias in the Workplace," InfoPro Learning, March 10, 2016, https://www.infoprolearning.com/blog/10-ways-you-can -reduce-bias-in-the-workplace/, accessed July 8, 2018.

20. McCormick, "The Real Effects of Unconscious Bias in the Workplace," 6. $n$ 